\title{
Prevalence, Sociodemographic Correlates and Associated factors of Somatoform and Whiteley Disorders among Internally Displaced Persons in Ogoja displacement settlements, Nigeria: A Cross- sectional Study
}

Ugbe Maurice-Joel Ugbe ( $\nabla$ mauricejoelph@unical.edu.ng )

University of Calabar

Ekpereonne Babatunde Esu

University of Calabar

Obiageli Chiezey Onwusaka

University of Calabar

Marvin Muji Bisongedam

University of Calabar

Joseph Ajah Efut

University of Calabar

Ofem Irom Ekpo

University of Calabar

\section{Research Article}

Keywords: Somatoform, Whiteley, Internally Displaced adults, illness, worry and conviction

Posted Date: January 20th, 2022

DOI: https://doi.org/10.21203/rs.3.rs-1279435/v1

License: (c) (i) This work is licensed under a Creative Commons Attribution 4.0 International License.

Read Full License 


\section{Abstract}

Experiences of displacement have been associated with the prevalence of various mental health disorders owing to certain factors. This study aimed to identify the prevalence, sociodemographic correlates, and other factors associated with Somatoform and Whiteley disorders among internally displaced adults in Ogoja displacement settlements, Nigeria. This was a cross-sectional study of 335 respondents. Somatoform and Whiteley disorders were assessed using the SOM-SCL and Whiteley-7 sections of the Common Mental Disorder Questionnaire while a semi-structured questionnaire was used to collect data on sociodemographic and displacement-related factors. Data were analyzed using descriptive statistics, Chi-square, and multivariable logistic regression. The prevalence of somatoform and Whiteley disorders was $59.1 \%$ and $84.8 \%$ respectively. Factors found to be significant in each bivariate Chi-square analysis were modeled for each mental disorder. The multivariate analysis revealed that being married $(\mathrm{AOR}=2.80 ; p=0.02)$ prolonged displacement $(\mathrm{AOR}=3.29 ; p=0.003)$, discrimination $(A O R=2.25 ; p=0.01)$, disease outbreak ( $A O R=1.92 ; p=0.03)$, loss of loved ones ( $A O R=1.34 ; p=0.028)$, overcrowded households (AOR $=2.30 ; p=0.008)$, and fear of reprisals ( $\mathrm{AOR}=2.05 ; p=0.026)$ were significantly associated with somatoform disorder. Younger ages, low income (AOR=5.43; $p=0.006)$, longer duration of displacement $(A O R=8.43 ; p=0.020)$, separation from family ( $A O R=4.19 ; p=0.004)$, and loss of loved ones ( $A O R=3.57 ; p=0.006)$ were significantly associated with Whiteley problems. The findings suggest that the high prevalence of the studied outcomes are related to many demographic factors, life stressors and events. A synergetic effort by different bodies in creating and routinely arranging mental health interventions for this population is recommended.

\subsection{Introduction}

Human displacement remains one of the most significant humanitarian challenges facing the world [1]. The global space has been plagued with rising new displacements annually due to crises and disasters. Despite novel frameworks from action in several countries, the primary concern with regards to the background of internal displacement are still sparsely being properly attended to [2]. Drivers of prolonged displacement include political crises, severe poverty, and global warming as most IDPs are making their way back to conflict-ridden areas without means of livelihoods. Globally, over 50.8 million persons have been displaced due to both conflicts or violence and disasters [2]. Further perusal into new displacements indicates that 8.5 million persons and 24.9 million persons were displaced by conflicts/ violence and disasters, respectively. $6.4 \%$ of the global total for new displacements for 2019 was recorded displacements from the Americas, $0.3 \%$ in Europe and Central Asia, $24.1 \%$ in Sub-Saharan Africa, 9.6\% in the Middle East and North Africa, 30\% in South Asia, and 29.6\% in East Asia and Pacific [2]. In Africa, there is a higher concentration of displacement due to conflicts and wars. Nigeria, Ethiopia, the Democratic Republic of Congo, Cameroon, and Sudan show the existing problems of displacement as the years go by [3]. There has been minimal will to subdue such situations from escalating, thus leading to the increased figures that are being presented each year. 
In Nigeria, it is estimated that $20-30 \%$ of the population suffers from mental disorders [4]. The World Health Organization's Assessment Instrument for Mental Health Systems (AIMS) 2006 highlighted the neglect of mental health issues in Nigeria. Besides, policy documents on psychological health were found to be outdated without further revisions to include situations of crises and violence that have plagued the country in present times [4]. Losing home, loved ones, and being destabilized has its ripple effects and leads to many adverse mental health outcomes. Kronick [5] stated that the prevalence of Common Mental Disorders in resettled refugees, who at some point also attained IDP status range from $4-44 \%$. The dangers of traumatic events cause fear, anxiety, and withdrawal [6]. Conflicts are followed by living in conditions of uncertainty, fear, somatic problems, and anxiety, which continue to impact the displaced persons negatively. While depression, anxiety and Post Traumatic Stress Disorder (PTSD) are more commonly explored among war affected persons, there is still paucity of data regarding Somatic Symptom Disorder and Whiteley problems among the aforementioned population. Somatoform disorder is known to manifest as physical disorders in the absence of any known underlying medical problems, while producing symptoms such as unexplained pains in the chest, abdomen, or limbs as well as sleeplessness [7]. Some of the risk factors associated with Somatoform disorder include exposure to traumatic conditions, comorbid mental conditions, and several socioeconomic deprivations, all of which are usually increased in conflict situations [7]. Despite the effect of this mental condition, limited studies have emerged from low-and middle-income countries where most of the world's IDPs reside. Only studies by Morina, Ford, Risch, Morina and Stangier [8] and Comellas, Makhashvili, Chikovani, Patel, McKee, Bisson and Roberts [9] have been able to magnify this situation in low resource settings. Whiteley disorder, sometimes referred to as hypochondriasis is characterized by illness, worry and conviction and has been grossly understudied among conflict and war-affected persons. American Psychiatric Association Diagnostic and Statistical Manual of Mental Disorders (DSM-5) as cited in Giardinelli [10] reported that victims of the acts of war report suffering from mild and severe mental distress, agitation, insomnia, generalized anxiety, and mild somatoform symptoms, like headaches and back pains.

Accordingly, this study aimed at examining the prevalence, socio-demographic correlates, and associated factors of somatoform and Whiteley disorders among internally displaced adults. Operationally, the study postulated 2 hypotheses to guide the study thus:

1. There is no statistically significant relationship between selected socio-demographic factors and diagnoses of somatoform and Whiteley disorders among internally displaced adults in the study area

2. There is no statistically significant relationship between displacement-related factors and diagnoses of somatoform and Whiteley disorders among internally displaced adults in the study area 


\subsection{Methods}

\subsection{Study Area, Scope and Design}

Ogoja Local Government Area is located in Cross River State, Nigeria, lying 6 ${ }^{\circ} 30^{\prime} \mathrm{N} 8^{\circ} 40^{\prime} \mathrm{E}$, about $300 \mathrm{~km}$ north of Calabar, the state capital [11]. It has an area of $972 \mathrm{~km}^{2}$ which is about $375 \mathrm{sq}$. mi and a population of 171,901 as of the 2006 population census. This study comprised adult IDPs aged 18 years and above who had been displaced by natural and man-made causes in Ogoja LGA. Data for this present study were collected from only indigenes of Nigeria who were displaced and now reside in the host communities in Ogoja.

This was a cross-sectional descriptive study employing a quantitative approach in determining the prevalence, sociodemographic correlates, and associated factors of somatoform and Whiteley disorders among displaced adults in the study area.

\subsection{Sample Procedure}

The sample size for this study was determined using Fischer's formula for estimating sample size of Cross-sectional studies.

$$
\mathrm{n}=\frac{Z \alpha^{2} p q}{d^{2}}
$$

$\mathrm{n}=$ calculated sample size; $\mathrm{Z}=$ Standard normal variate- 1.96 (at $95 \%$ confidence interval); $\mathrm{p}=$ proportion of prevalence of any CMD was 0.64 as reported in a study by Atsua, Garba and Oludi [12]; q = proportion without the outcome $(0.36)$; $d=$ margin of error for proportion being estimated $(0.05)$

$$
n=\frac{1.96^{2} \times 0.64 \times 0.36}{0.05^{2}}=354
$$

Adjusting for perceived non-response rate of $10 \%, n=393$

393 respondents were recruited to measure the study outcomes to within $5 \%$ precision and a $95 \%$ confidence interval.

\subsection{Sampling Procedure}

A multi-stage sampling technique using probability and non-probability methods was employed to recruit participants for the study. Due to the influx of IDPs in specific locations in the study setting, purposive sampling was utilized to select three wards majorly playing host to internally displaced persons in the study setting. Only wards that had a high IDP presence were selected for the study. Purposive sampling was used to select all ten communities of the three wards. Due to the hard-to-reach nature of IDPs and lack of reachable IDP settlements snowball sampling technique was used in identifying households or 
settlements where IDPs resided. Only one consenting adult IDP in each household was recruited using simple random sampling in cases of multiple adults in one household.

\subsection{Instruments for data collection}

A semi-structured questionnaire was used to collect demographic information of all respondents and displacement-related factors associated with Somatoform and Whiteley disorders. The SCL-SOM and Whiteley-7 sections of the Common Mental Disorder Questionnaire (CMDQ) were used to diagnose these 2 conditions. Items 1-12 on the CMDQ depict symptoms of somatoform disorder while items 13-19 are symptoms associated with Whiteley disorder. The CMDQ has proven to possess high diagnostic accuracy and exceptional external validity [13] and is a 36-Item questionnaire that covers signs and symptoms generally linked with Somatic Symptom Disorders (SSDs), general anxiety, depression, and substance use and abuse. Its questions are constructed by adopting symptoms criteria from the SCL-90-R [13]. Each question of is rated on a five-point Likert scale of distress with responses ranging from 'not at all to 'extremely' (0-4).

\subsection{Method of data collection}

Three trained research assistants were recruited for the study. The RAs were also recruited based on their knowledge of the local languages and navigation around the community. All the aforementioned instruments were interviewer-administered using Open Data Kit (ODK) collect software which was linked with Kobo tool box online database. A total of 335 displaced adults who gave their consents, were recruited, and were willing to participate.

\subsection{Method of data analysis}

Data were extracted from ODK collect and downloaded into Microsoft Excel to scan for entry completeness. Data were imported into and analyzed using Statistical Product and Service Provision version 23. All responses in the CMDQ were dichotomized between 'not at all' and 'a little' as validated by Christensen, Fink, Toft, Frostholm, Ørnbøl and Olesen [13]. This means that all positive responses between 'a little' and 'extremely' were recoded and counted as ' 1 ' while 'not at all' remained ' 0 '. There were no negative worded questions hence no need for recoding. Thresholds for case identification in both subscales were determined by the use of standardized theoretical optimal cut-off points regarding sensitivity and specificity [13]. A sum score of 5 or more in the somatoform subscale (SCL-SOM) depicts a somatoform disorder diagnosis with a sensitivity and specificity of 83/56; a sum score of 2 or more in the Whiteley subscale (Whiteley-7) depicts an illness and worry disorder diagnosis with a sensitivity and specificity of 75/52 [13]. Prevalence of somatoform and Whiteley disorders were determined using descriptive statistics. Pearson's Chi-Square was used to test bivariate associations in the disorders across demographic characteristics. Multivariate logistic regression analysis was used to estimate the odds of developing the outcomes with displacement-related factors while controlling for statistically significant demographic correlates. Adjusted Odds Ratios (AORs) were determined with a 95\% confidence interval (Cl). Other predictors of the outcomes were selected a priori based on data from relevant literature and 
our theoretical assumptions. Only factors that were associated with the outcomes of interest in the bivariate analysis were included in the respective multivariate analyses to eliminate the error of overadjusting without compromising identification of the predictors for the outcomes of interest. The significance threshold was set at $\alpha=0.05$.

\subsection{Results}

We gathered data from 335 respondents amounting to an $85 \%$ response rate. Table 1 presents demographic data of respondents. Over half of the respondents (51\%) were females. The mean age of the respondents in this present study was 34 years \pm 11 . Respondents' ages ranged between 18 and 74 . Majority of the respondents (63.3\%) were young adults while older adults were the least number of respondents (4.8\%). Most respondents were married (43.3\%). Most of the respondents had attained secondary education (36.4\%). Respondents were predominantly farmers. In terms of income, most respondents (57.9\%) earned below minimum wage. 
Table 1

Demographics of the study respondents

\begin{tabular}{|c|c|c|}
\hline Variables & Frequency & Percentage (\%) \\
\hline Gender & 164 & 49 \\
\hline Male & 171 & 51 \\
\hline \multicolumn{3}{|l|}{ Female } \\
\hline Age (in years) & 212 & 63.3 \\
\hline $18-35$ & 107 & 31.9 \\
\hline $36-55$ & 16 & 4.8 \\
\hline \multicolumn{3}{|l|}{$>55$} \\
\hline Marital Status & 87 & 26 \\
\hline Single & 145 & 43.3 \\
\hline Married & 22 & 6.6 \\
\hline Divorced & 50 & 14.9 \\
\hline Separated & 31 & 9.3 \\
\hline \multicolumn{3}{|l|}{ Widowed } \\
\hline Educational attainment & 68 & 20.3 \\
\hline No formal education & 83 & 24.8 \\
\hline Primary & 122 & 36.4 \\
\hline Secondary & 62 & 18.5 \\
\hline \multicolumn{3}{|l|}{ Tertiary } \\
\hline Occupation & 75 & 22.4 \\
\hline Unemployed & 26 & 7.8 \\
\hline Public Servant & 82 & 24.5 \\
\hline Business Owner & 152 & 45.4 \\
\hline \multicolumn{3}{|l|}{ Farmer } \\
\hline Household size & 202 & 60.3 \\
\hline $1-3$ & 133 & 39.7 \\
\hline 4 and greater & & \\
\hline
\end{tabular}




\begin{tabular}{|lll|}
\hline Variables & Frequency & Percentage (\%) \\
\hline Household income per month & 78 & 23.3 \\
No income earned & 198 & 57.9 \\
Below Minimum wage & 46 & 13.7 \\
Within minimum wage & 9 & 2.7 \\
Above minimum wage & 8 & 2.4 \\
I'd rather not say & & \\
Duration of displacement & 22 & 6.6 \\
About 1 month & 91 & 27.2 \\
$>1$ month- $<6$ months & 162 & 48.4 \\
$>6$ months to 12 months & 60 & 17.9 \\
$>12$ months & & \\
\hline
\end{tabular}

\subsection{Prevalence of Somatoform and Whiteley disorders in the study population}

The prevalence of somatoform disorder was $59.1 \%$ while there was $84.8 \%$ prevalence of illness, worry, and conviction (Whiteley) disorder (See Table 2).

Table 2

Prevalence of Somatoform and Whiteley disorders among respondents

\begin{tabular}{|lll|}
\hline CMD subtypes & Frequency $(\mathrm{n}=\mathbf{3 3 5})$ & Point prevalence $(\%)$ \\
\hline Somatoform & 198 & 59.1 \\
\hline Illness, worry, and conviction & 284 & 84.8 \\
\hline
\end{tabular}

\subsection{Test of hypotheses}

There is no statistically significant relationship between selected socio-demographic factors and diagnoses of somatoform and Whiteley disorders among internally displaced adults in the study area.

As can be seen by the frequencies cross-tabulated in Table 2 above and also corresponding $P$-values presented in Table 3 below, there is no statistically significant relationship between gender and somatoform disorder $\left(\chi^{2}=0.45, d f=1, p=0.52\right)$. There is also no statistically significant relationship between age and somatoform disorder among the study respondents $\left(\chi^{2}=2.99, \mathrm{df}=2, p=0.22\right)$. The proportion of respondents who reported developing somatoform disorder differed by marriage $\left(\chi^{2}=10.8\right.$ $\mathrm{df}=4, p=0.03$ ). Married respondents were more likely than other respondents to suffer from somatoform 
disorders. Hence, we reject the null hypothesis of no statistically significant relationship between somatoform disorder and marital status in the study population. The Chi-square test of independence also showed that there was a significant association between level of education and somatoform disorder among the study respondents $\left(X^{2}=9.38, \mathrm{df}=3, p=0.03\right)$. Those whose highest educational attainment was secondary education were more likely than other educational levels to develop the somatoform disorder in the study population. There was a significant association between the occupation of respondents and developing the somatoform disorder, $\chi^{2}=13.15 \mathrm{df}=3, p=0.004$. Hence, we reject the null hypothesis of no significant relationship between occupation and somatoform disorder.

There was also a significant relationship between respondents' income and somatoform disorder, $\chi^{2}=$ $29.1, \mathrm{df}=4, p<.001$. We however reject the null hypothesis of no significant relationship between income and somatoform disorder. Furthermore, there was a significant relationship between duration of displacement and somatoform disorder, $\chi^{2}=24.9, \mathrm{df}=3, p<.001$. In terms of family size, there was no significant relationship between the number of persons in a household and somatoform disorder, $\chi^{2}=$ $2.25, \mathrm{df}=1, p=.083$. We, therefore, fail to reject the null hypothesis. 
Table 3

Bivariate Chi-square analysis of relationship between demographic factors and somatoform disorder

\begin{tabular}{|c|c|c|c|}
\hline Variables & $\begin{array}{l}\text { Presence of somatoform }(\mathrm{N}, \\
\%)\end{array}$ & $\begin{array}{l}\text { Absence of somatoform (N, } \\
\%)\end{array}$ & $p$-Value \\
\hline Gender & $94(47.5)$ & $67(48.9)$ & 0.52 \\
\hline Male & $104(52.5)$ & $70(51.1)$ & \\
\hline \multicolumn{4}{|l|}{ Female } \\
\hline Age (in years) & $119(60.1)$ & $93(67.9)$ & \multirow[t]{4}{*}{0.23} \\
\hline $18-35$ & $67(33.8)$ & $40(29.2)$ & \\
\hline $36-55$ & $12(6.1)$ & $4(2.9)$ & \\
\hline \multicolumn{3}{|l|}{$>55$} & \\
\hline Marital Status & $42(21.2)$ & $45(32.8)$ & \multirow[t]{6}{*}{$0.03^{*}$} \\
\hline Single & $99(50)$ & $46(33.6)$ & \\
\hline Married & $11(5.6)$ & $11(8.0)$ & \\
\hline Divorced & $30(15.2)$ & $20(14.6)$ & \\
\hline Separated & $31(8.1)$ & $15(10.9)$ & \\
\hline \multicolumn{3}{|l|}{ Widowed } & \\
\hline Educational attainment & $33(16.7)$ & $35(25.5)$ & \multirow[t]{5}{*}{$0.03^{*}$} \\
\hline No formal education & $49(24.7)$ & $34(24.8)$ & \\
\hline Primary & $84(42.4)$ & $38(27.7)$ & \\
\hline Secondary & $32(16.2)$ & $30(21.9)$ & \\
\hline \multicolumn{3}{|l|}{ Tertiary } & \\
\hline Occupation & $31(15.7)$ & $44(32.1)$ & \multirow[t]{5}{*}{$0.004^{\star}$} \\
\hline Unemployed & $17(8.6)$ & $9(6.6)$ & \\
\hline Public Servant & $50(25.3)$ & $32(23.4)$ & \\
\hline Business Owner & $100(50.4)$ & $52(38.0)$ & \\
\hline \multicolumn{3}{|l|}{ Farmer } & \\
\hline Household size & $126(63.6)$ & $76(55.5)$ & \multirow[t]{3}{*}{0.083} \\
\hline $1-3$ & $72(36.4)$ & $61(44.5)$ & \\
\hline 4 and above & & & \\
\hline
\end{tabular}




\begin{tabular}{|c|c|c|c|}
\hline Variables & $\begin{array}{l}\text { Presence of somatoform ( } \mathrm{N}, \\
\%)\end{array}$ & $\begin{array}{l}\text { Absence of somatoform }(\mathrm{N} \text {, } \\
\%)\end{array}$ & $p$-Value \\
\hline $\begin{array}{l}\text { Household income per } \\
\text { month } \\
\text { No income earned } \\
\text { Below Minimum wage } \\
\text { Within minimum wage } \\
\text { Above minimum wage } \\
\text { I'd rather not say }\end{array}$ & $\begin{array}{l}35(17.7) \\
129(65.2) \\
25(12.6) \\
9(4.5) \\
0(0)\end{array}$ & $\begin{array}{l}43(31.4) \\
65(47.4) \\
21(15.3) \\
0(0.0) \\
8(5.8)\end{array}$ & $<.001^{*}$ \\
\hline $\begin{array}{l}\text { Duration of displacement } \\
\text { About } 1 \text { month } \\
>1 \text { month- }<6 \text { months } \\
>6 \text { months to } 12 \text { months } \\
>12 \text { months }\end{array}$ & $\begin{array}{l}7(3.5) \\
40(20.2) \\
115(58.1) \\
36(18.2)\end{array}$ & $\begin{array}{l}15(10.9) \\
51(37.2) \\
47(34.3) \\
24(17.5)\end{array}$ & $<.001 *$ \\
\hline
\end{tabular}

Table 4 below represents the relationship between sociodemographic characteristics and Whiteley disorder. There is a statistically significant and positive relationship between gender and Whiteley symptoms, $\chi^{2}=5.97, \mathrm{df}=1, p=0.02$. There is also a statistically significant relationship between the age of respondents and Whiteley symptoms, $\chi^{2}=8.63, \mathrm{df}=2, p=0.013$. The Chi-square analysis showed that there is no statistically significant relationship between marital status and positive Whiteley symptoms, $\chi^{2}=7.94, \mathrm{df}=4, p=0.09$. Furthermore, there was a statistically significant relationship between the level of education of respondents and positive Whiteley symptoms, $\chi^{2}=8.82, \mathrm{df}=3, p=0.03$. There was no statistical significant relationship between occupation and positive Whiteley symptoms, $\chi^{2}=3.40, \mathrm{df}=3$, $p=0.34$. There was a statistically significant relationship between respondents' income level and positive Whiteley symptoms, $\chi^{2}=25.8, \mathrm{df}=4, p<0.001$. Lastly, there was a statistically significant relationship between family size and positive Whiteley symptoms, $\chi^{2}=5.81, \mathrm{df}=1, p=0.02$. We, therefore, reject the null hypothesis. 
Table 4

Bivariate Chi-square analysis of relationship between demographic factors and Whiteley disorder

\begin{tabular}{|c|c|c|c|}
\hline Variables & $\begin{array}{l}\text { Presence of Whiteley } \\
\text { disorder (N, \%) }\end{array}$ & $\begin{array}{l}\text { Absence of Whiteley } \\
\text { disorder }(\mathrm{N}, \%)\end{array}$ & $p$-Value \\
\hline Gender & $131(46.1)$ & $33(64.7)$ & $0.02^{*}$ \\
\hline Male & $153(53.9)$ & $18(35.3)$ & \\
\hline \multicolumn{4}{|l|}{ Female } \\
\hline Age (in years) & $189(66.5)$ & $23(45.1)$ & $0.01 *$ \\
\hline $18-35$ & $83(29.2)$ & $24(47.1)$ & \\
\hline $36-55$ & $12(4.2)$ & $4(7.8)$ & \\
\hline \multicolumn{4}{|l|}{$>55$} \\
\hline Marital Status & $76(26.8)$ & $11(21.6)$ & 0.09 \\
\hline Single & $127(44.7)$ & $18(35.3)$ & \\
\hline Married & $15(5.3)$ & $7(13.7)$ & \\
\hline Divorced & 39 (13.7) & $11(21.6)$ & \\
\hline Separated & $27(9.5)$ & $4(7.8)$ & \\
\hline \multicolumn{4}{|l|}{ Widowed } \\
\hline \multirow{3}{*}{$\begin{array}{l}\text { Educational } \\
\text { attainment } \\
\text { No formal education }\end{array}$} & $56(19.7)$ & $12(23.5)$ & $0.03^{*}$ \\
\hline & $63(22.2)$ & $20(39.2)$ & \\
\hline & $109(38.4)$ & $13(25.5)$ & \\
\hline & $56(19.7)$ & $6(11.8)$ & \\
\hline \multicolumn{4}{|l|}{ Tertiary } \\
\hline Occupation & $61(21.5)$ & $14(27.5)$ & 0.34 \\
\hline Unemployed & $24(8.5)$ & $2(3.9)$ & \\
\hline Public Servant & $73(25.7)$ & $9(17.6)$ & \\
\hline Business Owner & $126(44.4)$ & $26(51.0)$ & \\
\hline Farmer & & & \\
\hline
\end{tabular}




\begin{tabular}{|llll|}
\hline Variables & $\begin{array}{l}\text { Presence of Whiteley } \\
\text { disorder (N, \%) }\end{array}$ & $\begin{array}{l}\text { Absence of Whiteley } \\
\text { disorder (N, \%) }\end{array}$ & $p$-Value \\
\hline Household size & $179(63)$ & $23(45.1)$ & 0.08 \\
1-3 & $105(37)$ & $28(54.9)$ & \\
\hline $\begin{array}{l}\text { Household income per } \\
\text { month }\end{array}$ & $53(18.7)$ & & $<0.001^{*}$ \\
No income earned & $172(60.6)$ & $25(49.0)$ & \\
Below Minimum wage & $44(15.5)$ & $22(43.1)$ & \\
Within minimum wage & $9(3.2)$ & $2(3.9)$ & \\
Above minimum wage & $6(2.1)$ & $0(0.0)$ & \\
I'd rather not say & & $2(3.9)$ & \\
\hline $\begin{array}{l}\text { Duration of } \\
\text { displacement }\end{array}$ & $14(4.9)$ & & \\
About 1 month & $79(27.8)$ & $8(15.7)$ & \\
$>$ 1 month- < 6 months & $137(48.2)$ & $12(23.5)$ & \\
$>$ 6 months to 12 & $54(19)$ & $25(49.0)$ & \\
months & & $6(11.8)$ & \\
$>$ 12 months & & & \\
\hline *Statistical significance based on p-Value < .05 & & \\
\hline 3.3 Hypothesis 2 & & \\
\hline
\end{tabular}

There is no statistically significant relationship between displacement-related factors and diagnoses of somatoform and Whiteley disorders among internally displaced adults in the study area.

As can be seen in Table 5 below, displacement-related factors significantly associated with somatoform disorder in the study population include discrimination as a result of present status, $\chi^{2}=16.6, \mathrm{df}=1, p<$ .001; outbreak of various diseases including COVID-19, $\chi^{2}=7.89, \mathrm{df}=1, p=0.01$; loss of loved ones due to crises or disasters, $\chi^{2}=18.3, \mathrm{df}=1, p<0.001$; living in overcrowded shelters, $\chi^{2}=9.54, \mathrm{df}=1, p=0.002$; fears over reprisal attacks or natural disasters, $\chi^{2}=15.5, \mathrm{df}=1, p<0.001$; lack of basic amenities, $\chi^{2}=$ $8.56, \mathrm{df}=1, p=0.003$; and concerns about health or safety, $\chi^{2}=7.1, \mathrm{df}=1, p=0.01$. In each of the above scenarios, we however reject the null hypothesis of no statistical significant relationship between displacement-related factors and somatoform disorder in the study population. 
Table 5

Bivariate Chi-square analysis of displacement-related factors associated with Somatoform disorder

\begin{tabular}{|c|c|c|c|}
\hline \multirow[t]{3}{*}{ Items } & \multicolumn{3}{|c|}{ Response categories } \\
\hline & Yes & No & p-Value \\
\hline & $\mathbf{N}(\%)$ & $\mathbf{N}(\%)$ & \\
\hline Stress at work & $142(71.7)$ & $56(28.3)$ & 0.25 \\
\hline Discrimination & $50(25.3)$ & $148(74.7)$ & $<0.001^{*}$ \\
\hline Financial strain & $190(96)$ & $8(4)$ & 0.07 \\
\hline Loss of loved ones in crises or natural disaster & $73(46.6)$ & $125(63.1)$ & $<0.001^{\star}$ \\
\hline Outbreak of diseases including COVID-19 & $187(94.4)$ & $11(5.6)$ & $0.01 *$ \\
\hline Overcrowded shelter & $76(38.4)$ & $122(61.6)$ & $0.002^{\star}$ \\
\hline Fears over reprisal attacks & $67(33.8)$ & $131(66.2)$ & $<0.001^{\star}$ \\
\hline Separated from family due to conflicts and/ or disasters & $85(43.4)$ & $111(56.6)$ & 0.06 \\
\hline Insufficient amenities & $180(91.8)$ & $16(8.2)$ & $0.003^{*}$ \\
\hline Domestic violence & $52(26.3)$ & $146(73.7)$ & 0.65 \\
\hline Concerns about safety and general health & $190(96)$ & $8(4)$ & $0.01^{*}$ \\
\hline
\end{tabular}

Table 6 indicates the distribution of chi-square $p$-values to establish the relationship between displacement-related factors and Whiteley disorder. The displacement-related factors significantly associated with Illness and worry disorder in the study population include discrimination as a result of present status, $\chi^{2}=19.2, \mathrm{df}=1, p<0.001$; loss of loved ones due to crises or disasters, $\chi^{2}(1, N=335)=$ 18.9, $p<0.001$; living in overcrowded shelters, $\chi^{2}=13.1, \mathrm{df}=1, p<0.001$; fears over reprisal attacks or natural disasters, $\chi^{2}(1, N=335)=9.89, p=0.002$; separation from family, $\chi^{2}(1, N=335)=14.8, p<0.001$; and concern about health or safety, $\chi^{2}=14.0, \mathrm{df}=1, p<0.001$. In each of the above scenarios, we however reject the null hypothesis of no statistical significant relationship between displacement-related factors and illness and worry disorder in the study population. 
Table 6

Bivariate Chi-square analysis of displacement-related factors associated with Whiteley disorder

\begin{tabular}{|c|c|c|c|}
\hline \multirow[t]{3}{*}{ Items } & \multicolumn{3}{|c|}{ Response categories } \\
\hline & Yes & No & p-Value \\
\hline & $N(\%)$ & $N(\%)$ & \\
\hline Stress at work & $213(75)$ & $71(25)$ & 0.34 \\
\hline Discrimination & $83(29.2)$ & $201(70.8)$ & $<0.001^{*}$ \\
\hline Financial strain & $269(94.7)$ & $15(5.3)$ & 0.21 \\
\hline Loss of loved ones in crises or natural disaster & $118(41.5)$ & $166(58.5)$ & $<0.001^{*}$ \\
\hline Outbreak of diseases including COVID-19 & $187(94.4)$ & $11(5.6)$ & $0.01 *$ \\
\hline Overcrowded shelter & $117(41.2)$ & $167(58.8)$ & $0.002^{\star}$ \\
\hline Fears over reprisal attacks & $111(39.1)$ & $173(60.9)$ & $0.002^{\star}$ \\
\hline Separated from family due to conflicts and/ or disasters & $122(43.3)$ & $160(56.7)$ & $0.001 *$ \\
\hline Insufficient amenities & 245 (86.9) & $37(13.1)$ & 0.51 \\
\hline Domestic violence & $68(23.9)$ & $216(76.1)$ & 0.16 \\
\hline Concerns about safety and general health & $270(95.1)$ & $14(4.9)$ & $<0.001^{*}$ \\
\hline
\end{tabular}

Table 7 shows the multivariate logistic regression analysis of the Sociodemographic correlates and other factors associated with the somatoform disorder after adjusting for all potential covariates that were found significant in the bivariate chi-square analysis. However, regardless of their significant status for each of the outcome variables, age and gender were included in all the multivariate models due to their biological relevance.

Being married was a positive and significant correlate of somatoform disorder in the study population, $b$ $=1.26, p=0.02, \mathrm{AOR}=2.80(95 \% \mathrm{Cl}: 1.17,6.73)$. This implies that displaced persons who are married are almost 3 times more likely than people in other marital groups to develop the somatoform disorder. The duration of displacement was also a positive and significant correlate of somatoform disorder in the study population, $b=1.19, p=0.003, \mathrm{AOR}=3.29(95 \% \mathrm{Cl}$. $954,11.3)$. In other words, persons displaced for between 6 months and 1 year are almost 4 times more likely to develop the somatoform disorder than those who may have been displaced for shorter periods. Being displaced for over a year showed positive but non-significant association with somatoform disorder, $b=0.41, p=0.55$, AOR $=1.51$ (95\% Cl: .385, 5.92). Discrimination because of present status showed a positive and significant relationship with development of somatoform disorder, $b=0.81, p=0.01$, AOR $=2.25$ ( $95 \% \mathrm{Cl}: 1.21,4.17$ ). Hence, those who were discriminated against because of their displacement status were 2.25 times more likely than 
those not discriminated against to develop the somatoform disorder in the study population. Being affected by the outbreak of diseases including the novel Coronavirus 2019 (COVID-19) showed a positive and significant relationship with the development of the somatoform disorder in the study population, $\mathrm{b}=$ $0.29, p=0.03, \mathrm{AOR}=1.92$ (95\% Cl: 1.07, 3.45). However, displaced persons who were affected by the outbreak of diseases within their displacement periods were 1.92 times more likely than those who were not affected to develop the somatoform disorder.

Furthermore, the multivariate analysis also found a positive and significant relationship between loss of loved ones due to crises or disasters and development of the somatoform disorder in the study population, $\mathrm{b}=0.65, p=0.03, \mathrm{AOR}=1.92(95 \% \mathrm{Cl}$ : $1.07,3.45)$. This implies that displaced persons who suffered the loss of loved ones due to crises or disasters were almost two times more likely than those who did not suffer losses to develop the somatoform disorder. There was also a positive and significant relationship between overcrowded shelters and developing the somatoform disorder in the study population, $\mathrm{b}=0.84, p=0.008, \mathrm{AOR}=2.30(95 \% \mathrm{Cl}: 1.25,5.26)$, implying that those who reported poor living conditions such as overcrowding were more than 2 times more likely than others who had better living conditions to suffer from the somatoform disorder. Fear over reprisal attacks or reoccurrence of natural disasters showed a positive and significant relationship with developing the somatoform disorder in the study population, $\mathrm{b}=0.72, p=0.03, \mathrm{AOR}=2.05$ (95\% Cl: $1.09,3.86)$, implying that displaced persons who had fear of reprisals and reoccurrence were over 2 times more likely than those without fears to develop the somatoform disorder.

However, female gender, older ages, primary and secondary educational attainment, and lower monthly income showed positive but non-significant relationships with developing the somatoform disorder in the study population (Table 8 ).

Table 7: Multivariate analysis of sociodemographic correlates, displacement-related factors, and Somatoform

disorder 


\begin{tabular}{|c|c|c|c|}
\hline Variables & AOR & $95 \% \mathrm{Cl}$ & $P$-Value \\
\hline \multicolumn{4}{|l|}{ Gender } \\
\hline Female & 1 & - & - \\
\hline Male & 0.71 & $0.39,1.27$ & 0.25 \\
\hline \multicolumn{4}{|l|}{ Age (in years) } \\
\hline $18-35$ & 1 & - & - \\
\hline $36-55$ & 1.11 & $0.59,2.07$ & 0.74 \\
\hline$>55$ & 3.29 & $0.79,13.6$ & 0.10 \\
\hline \multicolumn{4}{|l|}{ Marital Status } \\
\hline Single & 1 & - & \\
\hline Married & 2.80 & $1.17,6.73$ & $0.02^{*}$ \\
\hline Divorced & 1.06 & $0.29,3.78$ & 0.09 \\
\hline Separated & 1.51 & $0.54,4.21$ & 0.43 \\
\hline Widowed & 1.25 & $0.39,4.04$ & 0.71 \\
\hline \multicolumn{4}{|l|}{ Level of Education } \\
\hline No formal education & 1 & - & - \\
\hline Primary & 1.24 & $0.55,2.81$ & 0.61 \\
\hline Secondary & 1.48 & $0.68,3.19$ & 0.32 \\
\hline Tertiary & 0.54 & $0.19,1.53$ & 0.25 \\
\hline \multicolumn{4}{|l|}{ Occupation } \\
\hline Unemployed & 1 & - & - \\
\hline Public Servant & 1.96 & $0.37,10.8$ & 0.43 \\
\hline Business Owner & 1.74 & $0.62,4.84$ & 0.29 \\
\hline Farmer & 1.18 & $0.48,2.98$ & 0.70 \\
\hline \multicolumn{4}{|c|}{ Household Monthly Income } \\
\hline No income earned & 1 & - & - \\
\hline Below Minimum wage & 0.69 & $0.28,1.68$ & 0.42 \\
\hline
\end{tabular}
$(95 \%)$ 


\begin{tabular}{|c|c|c|c|}
\hline Variables & AOR & $95 \% \mathrm{Cl}$ & $P$-Value \\
\hline Within minimum wage & 0.37 & $0.12,1.16$ & 0.09 \\
\hline Above minimum wage & 250 & 0.001 & 0.99 \\
\hline I'd rather not say & - & - & - \\
\hline \multicolumn{4}{|l|}{ Duration of displacement } \\
\hline About 1 month & 1 & - & - \\
\hline$>1$ month $-<6$ months & 1.01 & $0.28,3.63$ & .985 \\
\hline$>6$ months to 12 months & 3.29 & $0.95,11.3$ & $.003^{\star}$ \\
\hline$>12$ months & 1.51 & $0.39,5.92$ & 0.56 \\
\hline \multicolumn{4}{|c|}{ Discriminated because of present status } \\
\hline No & 1 & - & - \\
\hline Yes & 2.25 & $1.21,4.17$ & $0.01 *$ \\
\hline \multicolumn{4}{|c|}{ Loss of loved ones due to crises or natural disasters } \\
\hline No & 1 & - & - \\
\hline Yes & 1.34 & $0.42,4.32$ & $0.03 *$ \\
\hline \multicolumn{4}{|c|}{ Outbreak of diseases including the COVID-19 affected you } \\
\hline No & 1 & - & - \\
\hline Yes & 1.92 & $1.07,3.45$ & $0.03^{*}$ \\
\hline \multicolumn{4}{|l|}{ Overcrowded shelter } \\
\hline No & 1 & - & - \\
\hline Yes & 2.30 & $1.25,4.26$ & $0.008^{\star}$ \\
\hline \multicolumn{4}{|c|}{ Fears over reprisal attacks or natural disasters } \\
\hline No & 1 & - & - \\
\hline Yes & 2.05 & $1.09,3.86$ & $0.03^{*}$ \\
\hline \multicolumn{4}{|c|}{ Concerned about health and safety } \\
\hline No & 1 & - & - \\
\hline Yes & 1.29 & $0.41,4.06$ & 0.66 \\
\hline
\end{tabular}


Table 8 shows the multivariate logistic regression analysis of the sociodemographic correlates and displacement-related factors associated with illness, worry, and conviction disorder after adjusting for all potential covariates that were found significant in the bivariate chi-square analysis. Though gender did not show significant association in the bivariate chi-square analysis, it was inputted in this model. Gender however showed a negative relationship with the Whiteley disorder, meaning that, males were less likely than females to develop illness, worry, and conviction problems in the study population, $\mathrm{b}=-0.82, p=$ $0.06, A O R=0.44(95 \% \mathrm{Cl}: 0.19,1.04)$. This relationship was however non-significant. Though age and Whiteley had no significant associations in the bivariate analysis, the multivariate analysis showed that age was a significant correlate of the outcome. Displaced persons who were middle-aged $[b=-1.53, p=$ 0.002 , AOR $=0.22(95 \% \mathrm{Cl}: 0.08,0.57)]$ and older $[b=-2.36, p=0.006, \mathrm{AOR}=0.09(95 \% \mathrm{Cl}: 0.02,0.51)]$ were less likely than younger adults (18-35 years) to develop the Whiteley disorder. Public servants were less likely than the unemployed to develop Whiteley problems, $b=-3.26, p=0.02, \mathrm{AOR}=0.04$ (95\% Cl: 0.003 , 0.59). Those who were business owners showed a positive, non-significant relationship with the outcome while being a farmer showed a negative, non-significant relationship with the outcome. Income was positively and significantly associated with the outcome. Respondents earning between below minimum wage were more likely than those earning below minimum wage to develop the outcome, $b=1.69, p=$ $0.006, \mathrm{AOR}=5.43(95 \% \mathrm{Cl}: 1.62,18.2)$. Also, those earning above minimum wage were more likely to develop the outcome than the other groups, $b=4.71, p=0.001$, AOR $=110.9(95 \% \mathrm{Cl}: 6.86,1792.6)$. The duration of displacement was also a positive and significant correlate of Whiteley disorder in the study population, $b=2.13, p=0.020, A O R=8.43(95 \% \mathrm{Cl}: 1.41,50.5)$. There were positive and significant relationships between being separated from family $[b=1.43, p=0.004$, AOR $=4.19(95 \% \mathrm{Cl}: 1.59,11.1)]$ and loss of loved ones due to crises and/or disasters $[b=1.27, p=0.006, A O R=3.57(95 \% \mathrm{Cl}: 1.44,8.86)]$ with developing Whiteley disorder in the study population. This implies that displaced persons in the study population who had been separated from their families and had lost loved ones as a result of crises and/ or disaster were more likely (4.19 and 3.57 times respectively) to develop illness, worry, and conviction disorder. 
Table 8

Multivariate analysis of sociodemographic correlates, displacement-related factors and Whiteley disorder

\section{Variables}

Gender

Female

Male

Age (in years)

$18-35$

$36-55$

$>55$

Level of Education

No formal education

Primary

Secondary

Tertiary

Occupation

Unemployed

Public Servant

Business Owner

Farmer

Household Monthly Income

No income earned

Below Minimum wage

Within minimum wage

Above minimum wage

I'd rather not say

Duration of displacement

About 1 month
AOR

$95 \% \mathrm{Cl}$

$P$-Value
0.44
$0.19,1.04$
0.06

1

0.22

0.09

$0.02,0.51$ $0.002^{\star}$

$0.006^{*}$

$\begin{array}{ll}0.08,0.57 & 0.002^{\star} \\ 0.02,0.51 & 0.006^{*}\end{array}$

1

0.62

0.69

1.09

1

0.04

1.19

0.43

0.12

$0.28,5.18$

0.81

1.52
0.39

0.51

0.91

$0.25,4.80 \quad 0.91$

\begin{tabular}{lll}
1 & - & - \\
\hline 5.43 & $1.62,18.2$ & 0.006 * \\
\hline 110.87 & $6.86,17892.6$ & 0.001 * \\
\hline 0.89 & $0.07,11.3$ & 0.93
\end{tabular}

1 (95\%) 


\begin{tabular}{|c|c|c|c|}
\hline Variables & AOR & $95 \% \mathrm{Cl}$ & $P$-Value \\
\hline$>1$ month $-<6$ months & 1.97 & $0.46,8.33$ & .360 \\
\hline$>6$ months to 12 months & 3.30 & $0.83,13.11$ & 0.09 \\
\hline$>12$ months & 8.43 & $1.41,50.5$ & $0.02 *$ \\
\hline \multicolumn{4}{|c|}{ Discriminated because of present status? } \\
\hline No & 1 & - & - \\
\hline Yes & 2.423 & 0.95 & 6.21 \\
\hline \multicolumn{4}{|c|}{ Loss of loved ones due to crises or natural disasters } \\
\hline No & 1 & - & - \\
\hline Yes & 3.57 & $1.44,8.86$ & $0.006^{*}$ \\
\hline \multicolumn{4}{|l|}{ Overcrowded shelter } \\
\hline No & 1 & - & - \\
\hline Yes & 2.42 & $0.97,6.04$ & 0.06 \\
\hline \multicolumn{4}{|c|}{ Fears over reprisal attacks or natural disasters } \\
\hline No & 1 & - & - \\
\hline Yes & 0.73 & $0.28,1.90$ & 0.51 \\
\hline \multicolumn{4}{|c|}{ Separated from family due to conflicts and/ or disasters } \\
\hline No & 1 & - & - \\
\hline Yes & 4.19 & $1.59,11.08$ & $0.004^{*}$ \\
\hline \multicolumn{4}{|c|}{ Concerned about health and safety } \\
\hline No & 1 & - & - \\
\hline Yes & 0.39 & $0.09,1.54$ & 0.18 \\
\hline \multicolumn{4}{|c|}{$\begin{array}{l}\text { *Statistical significance based on p-Value }<.05 \text {; AOR= Adjusted Odds Ratio; Cl= Confidence Interval } \\
(95 \%)\end{array}$} \\
\hline
\end{tabular}

\subsection{Discussion}

\subsubsection{Disorders among IDPs}

Overall, the results of this present study show a high prevalence of the outcomes in the study area. Although there is a paucity of data on identified somatic symptoms among displaced persons in the African region, a Ugandan study by Amone-P'Olak and Omech [14] found that the prevalence of somatic 
symptoms among war-affected displaced youths in Northern Uganda was $28.4 \%$. Mölsä, Punamäki, Saarni, Tiilikainen, Kuittinen and Honkasalo [15] in another East-African study also found the prevalence of somatic discomforts to be $43.8 \%$ among Somalis displaced in Finland. Also, Ethiopian migrant returnees who were displaced by their rapid migration to and from the Middle East and South Africa were $40.6 \%$ symptomatic of somatoform [16]. Similarly, a Ukrainian study by Herasymenko, Isakov, Halchenko and Kydon [17] found that there was a $46.5 \%$ prevalence of somatoform problems. All of these figures are moderately lower than the prevalence found in this study (59.1\%). These disparities in prevalence across the different studies may be due to the differences in methodology as well as the standardized instruments used. Mölsä, Punamäki, Saarni, Tiilikainen, Kuittinen and Honkasalo [15] used the General Health Questionnaire (GHQ-12), Amone-P'Olak and Omech [14] used the African Youth Psychosocial Assessment Instrument (APAI), and the Symptoms Checklist-90-Revised-SCL-90-R was used by Herasymenko, Isakov, Halchenko and Kydon [17]. Our study gives results in terms of the presence or absence of the condition according to the core symptoms defined in the WHO-International Classification of Disease-10 Revision. Disparities in prevalence across geographical lines may also be a result of higher levels of trauma in the different home countries at different periods.

Most displaced persons were symptomatic of Whiteley problems in this present study. The prevalence of this disorder among displaced persons was a high $84.8 \%$. The presence of persons with this outcome in the study population makes this finding consistent with the study by Herasymenko, Isakov, Halchenko and Kydon [17] who found similar thinking problems to be manifested in the form of hypochondriacal thoughts. The prevalence of this (55.2\%) was somewhat lower than that found in this present study. An even lower figure showed that the prevalence of this condition characterized by severe problems and concerns in daily self-care was $24.1 \%$ among Somalis displaced in Finland [15]. Again, these differences may be due to methodological disparities as well as geographical disparities and time.

\subsubsection{Sociodemographic correlates of the outcomes among IDPs in the study setting}

Although gender was not significantly associated with symptoms of somatoform in this study, the multivariate analysis showed that females were more likely than males to develop this condition. This is consistent with similar findings by Amone-P'Olak and Omech [14] who identified more female participants in Uganda to suffer from somatic symptoms than their male counterparts. This may be because women may have lived longer in captivity. Females may also be more at risk of these symptoms because of their vulnerability as they are more likely to experience Gender abuse and domestic violence than males, hence this finding. Being married was positively and significantly associated with being symptomatic to somatoform. Though not significantly associated with somatoform in the bivariate analysis, domestic violence $(p=0.65)$ which occurred more frequently in females in this study could be a possible reason for this finding. This is consistent with a Ugandan study by Amone-P'Olak and Omech [14] which found being married as a significant predictor of somatoform disorder.

In the bivariate analysis, secondary educational attainment and farming as an occupation were found to be significantly associated with symptoms of somatoform disorder. However while controlling for other 
factors, educational attainment and occupation had no significant relationship with this condition. No previous studies have been found to establish the relationship between this condition and education. Farming may be associated with this condition because of the strain the human body goes through in the process as well as the prolonged duration of their farming activities. Cheung, Makhashvili, Javakhishvili, Karachevsky, Kharchenko, Shpiker and Roberts [7] in their Ukrainian study found an occupation to be significantly associated with being symptomatic to somatoform. In the bivariate analysis, earning less income also showed a significant association with being symptomatic to somatoform among the study participants. In the multivariate analysis, however, this was not found significant. Though studies by Cheung, Makhashvili, Javakhishvili, Karachevsky, Kharchenko, Shpiker and Roberts [7], Mölsä, Punamäki, Saarni, Tiilikainen, Kuittinen and Honkasalo [15], and Amone-P'Olak and Omech [14] found low income to be predictors of somatoform symptoms, this study found no associations. This disparity may be a result of the fewer respondents in this present study earning no income.

Furthermore, prolonged displacement was also positively and significantly associated with somatoform in the study population. Persons displaced for longer durations were almost 4 times more likely than persons displaced for shorter periods to develop the outcome. This is consistent with a Sri Lankan study that found a significant relationship between prolonged displacement and somatization [18]. This is also consistent with studies by Mölsä, Punamäki, Saarni, Tiilikainen, Kuittinen and Honkasalo [15] and Amone-P'Olak and Omech [14]. A possible reason for this is that displacement for long periods leads to exposure to many vices such as poor host community acceptance and hence further attacks; frustration leading to domestic violence; economic crises due to increasing population; inflation, etc.

Whiteley problems were a major concern in this population. Age was found to be significantly associated with Whiteley symptoms. Younger adults aged 18-35 years were more likely than older counterparts to be symptomatic of this condition. This was consistent with a study that found that younger displaced adults (18-24 years) were at greater risk of being symptomatic to worry [19]. Also consistent with this was a study by Amone-P'Olak and Omech [14] which found displaced young persons to suffer from conviction issues in Northern Uganda. This could be as a result of the desire for greater autonomy, limited access to technology, quality of family life and relationships, the tendency of being bullied by older folks, vulnerability to sexual abuse, dependence on family to meet needs, and concerns that their current status may have truncated their ambitions.

Displaced persons who earned below and within minimum wage were more likely than persons who earned more to suffer from Whiteley problems. This was found to be consistent with a study by Herasymenko, Isakov, Halchenko and Kydon [17] which found that lower-income status was significantly associated with illness, worry, and conviction among displaced persons. This in part maybe because their respective income does not meet their various needs especially in this period of inflation. Also, the duration of displacement was significantly associated with this outcome. This is because a longer stay in displacement can lead to series of thoughts and ill feelings about self-worth.

\subsubsection{Factors associated with the outcomes among IDPs in Ogoja}


Discrimination, being affected by the outbreak of diseases including the COVID-19, loss of loved ones due to conflicts and/ or disasters, overcrowded shelters, and fear of reprisal attacks or natural disasters were factors most significantly associated with being symptomized to somatoform disorder in the study population. Amone-P'Olak and Omech [14] also found that harm to loved ones was significantly associated with being symptomized to somatoform among displaced persons in Northern Uganda. This present study also agrees with findings by Amone-P'Olak and Omech [14] that identified an outbreak of other disease stressors, stigma, discrimination, and poor community relations to be significantly associated with somatoform symptoms. Orendain and Djalante [20] cited that displaced persons were more likely to be affected by the COVID-19 because of some of their overcrowded shelters, barriers to access to social services and health care, and financial insecurity. Fear of reprisal attacks may be an associated factor of somatoform symptoms because due to this, people continue to migrate without any permanent shelter. In the course of migration, they may be exposed to psychological stressors that may reflect on their physical body. Some may encounter more attacks as a result of their migration status.

Separation from family and loss of loved ones due to crises and/ or disasters were significantly associated with being symptomatic to illness, worry, and conviction in this present study. This was consistent with a study by Amone-P'Olak and Omech [14] which found separation from family, a threat to loved ones, harm to loved ones, and death of loved ones to be significantly associated with developing symptoms of this outcome. The Whitney disorder is a comorbidity of somatoform disorder that has weakened psychological wellbeing [15].

\subsection{Conclusion}

This study highlights the prevalence and correlates of Somatoform and Whiteley disorder among IDPs in Ogoja LGA, Nigeria. The findings suggest that the high prevalence of the outcomes studied may be related to many life stressors and events. In other words, the findings suggest rising rates of mental health problems consistent with those from previous literature globally.

\subsection{Implications}

Addressing these mental health needs of IDPs requires a combined effort from individuals, humanitarian agencies, medical workers, governments, and researchers to carry out interventions based on broad public health approaches. At the community, it is common for displaced persons to experience hostilities in their host communities due to their displacement status. Most of them get disabled or die due to traumatizing and humiliating circumstances by way of discrimination and stigmatization. From a societal point of view, making efforts to address this issue of intolerance among host communities should constitute a higher priority. Mental health facilities should be made a priority to foster reintegration efforts of IDPs.

\subsection{Limitations}


This is a cross-sectional study hence some findings should be read with caution. Secondly, factors studied in this present study were self-reported and may be affected by recall bias. Longitudinal studies on evidence-based interventions for mental health will help to address these factors.

\section{Declarations}

\section{Funding}

No funding was received for conducting this study

\section{Conflicts of interest}

None declared

\section{Data availability}

Datasets generated from this present study are not publicly available due to respondents' confidentiality but are available on reasonable request from the corresponding author.

\section{Code availability}

None available

\section{Authors' contributions}

Authors Ugbe Maurice-Joel Ugbe and Esu, Ekpereonne Babatunde conceived the study and were involved in all processes of data acquisition, analysis, and interpretation of the results. Bisongedam Marvin Muji, Efut Joseph Ajah, and Ekpo Ofem Irom were involved in the collection of data and analysis. Author Onwusaka Obiageli Chiezey was involved in the critical review of the research contents.

\section{Ethical approval}

Ethical approval was obtained from the Ethics and Research Committee of the Cross River State, Ministry of Health, Calabar, Nigeria. Participants were assured of confidentiality of all data provided. Participants were not being compelled to be recruited and opting out of the survey was strictly at their discretion. Generally, this study was developed and carried out in accordance with the ethical standards as implemented in the 1964 Declaration of Helsinki and its later amendments.

\section{References}

1. Eweka O, Olusegun TO. Management of internally displaced persons in Africa: Comparing Nigeria and Cameroon. Afr.Res. Rev. 2016; 10, (1): pp. 193-210

2. http://www.internal-displacement.org/sites/default/files/publications/documents/2020-IDMCGRID.pdf 
3. http://www.internal-displacement.org/sites/default/files/publications/documents/2019-IDMCGRID.pdf

4. Suleiman DE. Mental health disorders in Nigeria: A highly neglected disease. Annals of Nigerian Medicine. 2016; 10, (2): pp. 47

5. Kronick R. Mental health of refugees and asylum seekers: assessment and intervention. Can J Psychiatry 2018; 63, (5): pp. 290-296

6. Oladeji O, Oladeji B, Chamla D, Safiyanu G, Mele S, Mshelia H, Agbor J. Sexual violence-related pregnancy among internally displaced women in an internally displaced persons camp in northeast Nigeria. J. Interpers. Violence. 2018; 0: pp. 1-13

7. Cheung A, Makhashvili N, Javakhishvili J, Karachevsky A, Kharchenko N, Shpiker M, Roberts B. Patterns of somatic distress among internally displaced persons in Ukraine: analysis of a crosssectional survey. Soc Psychiatry Psychiatr Epidemiol. 2019; 54, (10): pp. 1265-1274

8. Morina N, Ford JD, Risch AK, Morina B, Stangier U. Somatic distress among Kosovar civilian war survivors: relationship to trauma exposure and the mediating role of experiential avoidance. Soc Psychiatry Psychiatr Epidemiol. 2010; 45, (12): pp. 1167-1177

9. Comellas RM, Makhashvili N, Chikovani I, Patel V, McKee M, Bisson J, Roberts B. Patterns of somatic distress among conflict-affected persons in the Republic of Georgia. J. Psychosom. Res. 2015; 78, (5): pp. 466-471

10. Giardinelli L. Mental health and psychosocial needs and response in conflict-affected areas of northeast Nigeria. Humanitarian Exchange. 2017; 70: pp. 27-29

11. Omara-Achong T, Edwin-Wosu N, Edu E, Nkang A. Survey of indigenous vegetables species in parts of Ogoja and Calabar, Cross River State, Nigeria. Eur. J. Exp. Biol. 2012; 2, (4): pp. 1289-1301

12. Atsua TG, Garba CH, Oludi P. Prolonged Internal Displacement and Common Mental Disorders among Internally Displaced Persons in Benue State, Nigeria. The Nigerian Educational Psychologists. 2017; 15, (1): pp. 167-177

13. Christensen KS, Fink P, Toft T, Frostholm L, Ørnbøl E, Olesen F. A brief case-finding questionnaire for common mental disorders: the CMDQ. Fam. Pract. 2005; 22, (4): pp. 448-457

14. Amone-P'Olak K, Omech B. Predictors of Somatic Symptomatology in War-Affected Youth in Northern Uganda: Findings from the WAYS Study. Psychol Stud. 2020; 65, (2): pp. 182-190

15. Mölsä M, Punamäki R-L, Saarni SI, Tiilikainen M, Kuittinen S, Honkasalo M-L. Mental and somatic health and pre- and post-migration factors among older Somali refugees in Finland. Transcult. Psychiatry. 2014; 51, (4): pp. 499-525

16. Habtamu K, Minaye A, Zeleke WA. Prevalence and associated factors of common mental disorders among Ethiopian migrant returnees from the Middle East and South Africa. BMC Psychiatry. 2017; 17, (1): pp. 144

17. Herasymenko LO, Isakov RI, Halchenko AV, Kydon PV. Clinical features of adjustment disorder in internally displaced women. 2020 
18. Siriwardhana C, Adikari A, Pannala G, Siribaddana S, Abas M, Sumathipala A, Stewart R. Prolonged Internal Displacement and Common Mental Disorders in Sri Lanka: The COMRAID Study. PLoS One. 2013; 8, (5): pp. e64742

19. Levy BS, Sidel VW. Health Effects of Combat: A Life-Course Perspective. Annu. Rev. Public Health. 2009; 30, (1): pp. 123-136

20. Orendain DJA, Djalante R. Ignored and invisible: internally displaced persons (IDPs) in the face of COVID-19 pandemic. Sustain Sci. 2021; 16, (1): pp. 337-340 